\title{
Utilizando o Vídeo Para o Ensino dos Modelos Atômicos
}

\author{
Rubem Olino da Rosa 1 , Ricardo de Sousa Costa ${ }^{2}$ \\ 1,2 Universidade Federal de Rondônia (UNIR)
}

Palavras-Chave: Vídeo apoio, Modelos Atômicos, Física Moderna, Ensino de Física.

\section{Introdução}

Desde os seus primórdios, o átomo tem desempenhado um papel essencial na estruturação de inúmeras hipóteses, conceitos e teorias na Física, seja como protagonista ou como coadjuvante. O conhecimento grego, e o atomismo em particular, foi objeto de estudo por muitos físicos, alguns deles formuladores da Mecânica Quântica, que em livros, artigos, conferencias, expressaram publicamente o apreço pela origem e pela história da sua ciência. Em 1948, Erwing Schrödinger (1887-1961) fez uma série de palestras sobre a ciência grega. Sentia- se na obrigação de explicar que o seu interesse pelos antigos não era um mero passatempo pessoal. Schrödinger objetivava reunir elementos para uma visão mais crítica da ciência atual.

A hipótese atômica é retomada no século XVII, quando acorda do seu sono profundo para não mais adormecer. $O$ átomo encontra uma ciência que começa a ser regida por novas regras. Neste trabalho iremos acompanhar o átomo nos trilhos da história. Os tempos são outros. São tempos do experimento controlado que coloca o conhecimento num novo patamar.

A estrutura do átomo é um tema que os alunos apresentam dificuldade de compreensão, dado o nível de abstração, o que não é de se estranhar, uma vez que as ideias básicas sobre a teoria atômica, que surgiram em 1808 e 1810 com John Dalton, já descreviam a matéria composta por partículas muito pequenas para serem vistas, chamadas de átomos (PEDUZZI, 2005).

O estudo das partículas que compõe o átomo, como interagem entre si, a força e a energia que envolve suas ligações levaram dois séculos para serem compreendidas. Os modelos atômicos foram evoluindo à medida que novas experiências foram sendo feitas e novos resultados foram sendo observados. Atualmente é quase impossível duvidar da existência destas partículas.

Neste trabalho, através de vídeos, abordamos o desenvolvimento histórico dos modelos atômicos (SOUZA,2006) e as dificuldades que os alunos têm de compreende-los e diferenciálos. O uso inadequado dos modelos atômicos consagrados para explicar fenômenos experimentais pode induzir os alunos a cometerem certos equívocos.

\section{Metodologia e Material}

A aplicação do nosso trabalho correu em três etapas. Além de uma pesquisa nos livros didáticos sobre modelos atômicos, foram elaborados e aplicados dois questionários escritos, com perguntas objetivas e abertas. Num primeiro momento foi realizada uma pesquisa em quatro escolas de Ji-Paraná, Estado de Rondônia, para sondagem dos alunos do Ensino Médio, sobre os modelos atômicos. As escolas onde foram aplicados o questionário foram: E. E. E. F. M. Cel. Jorge Teixeira de Oliveira, distrito de Nova Londrina, E. E. E. F. M. Janete Clair, ambas escolas estaduais. IFRO - Instituto Federal de educação, ciência e Tecnologia de Rondônia, campus de Ji-Paraná/RO, escola federal. CEDUSP - Centro Educacional São Paulo, escola particular. Todas escolas do município de Ji-Paraná/RO.

Uma vez escolhido e analisado o perfil primário das instituições, foi elaborado um questionário, cuja finalidade é contribuir para a descrição do perfil dos alunos, a partir de respostas diretas e indiretas sobre a evolução dos modelos atômicos. A aplicação do questionário de sondagem foi para averiguar a formação do aluno, o que a escola oferece de tecnologia para o desenvolvimento das práticas pedagógicas, se a informática está sendo usado na disciplina de Física e principalmente verificar o que os alunos realmente sabem sobre os modelos atômicos.

Este primeiro questionário, foi composto por três partes distintas, as duas primeiras com perguntas sobre o estudante e a escola, com o objetivo de caracterizar os sujeitos e o local da pesquisa, a terceira parte deste questionário foi um conjunto de perguntas relacionadas

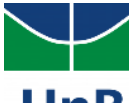


aos Modelos Atômicos. Este questionário era constituído de 07 perguntas diversificadas e semiestruturada, relacionadas a questões socioeconômicas, institucionais e ainda relacionadas à evolução dos modelos atômicos. Feita esta etapa, foi iniciada a segunda etapa. Na escola E. E. E. F. M. Cel. Jorge Teixeira de Oliveira foi proposta uma Oficina sobre os Modelos Atômicos para as turmas do $2^{\circ} \mathrm{A}$ e $2^{\circ} \mathrm{B}, 3^{\circ} \mathrm{A}$ e $3^{\circ} \mathrm{B}, 1^{\circ} \mathrm{EJA}$ noturno e $3^{\circ} \mathrm{EJA}$ diurno. Para as turmas do $2^{\circ} \mathrm{B}$, $3^{\circ} \mathrm{B}$ e $3^{\circ}$ EJA foi solicitada uma pesquisa/livre preliminar à oficina sobre os modelos atômicos. A oficina foi realizada no Laboratório de Informática da Escola. Para a apresentação foi usado dois aparelhos de Power Point, a cartilha ilustrativa para os alunos acompanharem 0 desenvolvimento dos modelos e a lousa para demostrar as fórmulas e os cálculos envolvidos. Era alternado a explicação do Power Point com o Vídeo. Os alunos tinham total liberdade de questionar imagens, fórmulas e tudo o que despertasse interesse e atenção. Na terceira etapa abrangeu-se sobre o estudo dos modelos atômicos, com conceitos que supostamente foram desenvolvidos em sala com os estudantes no decorrer do curso escolar. Nesta parte solicita-se para que os estudantes desenhem os modelos atômicos já conhecidos.

\section{Resultados e Discussão}

Durante a pesquisa, buscamos compreender qual era o nível de conhecimento dos alunos acerca da evolução dos modelos atômicos, bem como suas características e/ou particularidades. A tabela 1 faz uma relação entre o que os alunos aprenderam sobre o átomo, onde 104 alunos informaram que é a menor parte da matéria, 32 informaram que algo indivisível, 19 informaram que o átomo pode ser visto num microscópio eletrônico e apenas três alunos não responderam.

Tabela 1 -Modelo Atômico

\begin{tabular}{|c|c|}
\hline Sobre o Atómo aprendi que & Alunos \\
\hline E a menor parte da matéria & 104 \\
\hline$\dot{E}$ indivisível & 32 \\
\hline Pode ser visto num microscópio Eletrônico & 19 \\
\hline Não reponderam & 03 \\
\hline
\end{tabular}

Fonte: Autores

A tabela 2 descreve a quantidade de modelos atômicos que cada aluno estudou, em linhas gerais tinham a opção de marcar todos os modelos abaixo, caso ele tivesse estudado.

Tabela 2 -Modelos Atômicos Estudados

\begin{tabular}{|c|c|}
\hline Qual desse Modelos Você jà Estudou & Alunos \\
\hline Modelo atômico de Dalton & 107 \\
\hline Modelo atômico de Thompson & 81 \\
\hline Modelo atômico de Rutherford & 82 \\
\hline Modelo atômico de Bohr & 69 \\
\hline Modelo atômico quântico & 53 \\
\hline
\end{tabular}

Fonte: Autores

\section{Conclusões}

A conclusão que podemos chegar depois desta pesquisa é que os conteúdos básicos da Física, como o atomismo, são baseados em um enfoque excessivamente simplista da concepção de como a matéria é formada. Os estudantes não conseguem perceber a imensidão de conceitos envolvidos e como tudo o que está nos livros tem uma história de pesquisa, experiências, debates e descobrimentos. A ideia que se tem é que tudo apareceu "meio pronto" e foi bem fácil sistematizar. Percebemos o choque que os estudantes tiveram quando começaram a compreender o que envolve um modelo, uma teoria e o que se exige, no mundo cientifico, para que uma teoria seja aceita. Por trás das grandes verdades da Física, a maioria dos estudantes jamais havia pensado que há cálculos monumentais a serem feitos.

\section{Referências}

PEDUZZI, L. O. Q.; BASSO, A. C. Para o ensino do átomo de Bohr no nível médio. Revista Brasileira de ensino de Física, v. 27, n. 4, p. 545-557, 2005.

SOUZA, V.C.; JUSTI, R.; FERREIRA, P.F.M. Analogias utilizadas no ensino dos modelos atômicos de Thomson e Bohr: uma análise crítica sobre o que os alunos pensam a partir delas.

Rev. Investigações em Ensino de Ciências, v. 2, n. 1, p. 7-28, 2006. 